\title{
DEVELOPMENT OF A DIRECT METHOD OF ANALYZING TRANEXAMIC ACID LEVELS IN WHITENING CREAM USING REVERSED PHASE HIGH-PERFORMANCE LIQUID CHROMATOGRAPHY
}

\author{
BAITHA PALANGGATAN MAGGADANI, JIHAN YASMINA, HARMITA HARMITA*
}

Department of Pharmacy, Faculty of Pharmacy, Universitas Indonesia, Depok, Indonesia. Email: igakadeharmita@gmail.com

Received: 26 September 2019, Revised and Accepted: 17 December 2019

ABSTRACT

Objective: Whitening cream is a cosmetic that contains ingredients that can alleviate hyperpigmentation. Tranexamic acid (TA) is one of the potential anti-pigmentation agents that work through inhibiting plasmin. TA is used in cosmetic formulations at a concentration of $2.5 \%$ as a whitening and moisturizing agent. To date, research on TA in both cosmetics and other pharmaceutical products using high-performance liquid chromatography (HPLC) has not been done directly (without derivatization). Therefore, this study aimed to develop a simple and rapid analytical method for TA (without derivatization) in cosmetic cream samples using reverse-phase HPLC and water as a solvent.

Methods: Optimization was conducted by evaluating several parameters that affect sample extraction, as well as composition and mobile phase types. The optimal method must fulfill suitability and validation requirements. The optimal method should be able to detect and quantify TA in cream samples without derivatization.

Results: The optimal analysis condition used a ultraviolet detector at a wavelength of $210 \mathrm{~nm}$, acetonitrile: double-distilled water: phosphoric acid (64:34:2) as the mobile phase and a flow rate of $0.8 \mathrm{~mL} / \mathrm{min}$. The retention time of the analyte occurred in the $2^{\text {nd }} \mathrm{min}$.

Conclusion: The analytical method that met the validation requirements was characterized using parameters such as accuracy, precision, linearity, selectivity, limit, of detection, and limit of quantitation. This method is applicable for analyzing TA content in samples with a concentration of $1.02 \%$.

Keywords: Reverse-phase high-performance liquid chromatography, Optimization and validation, Tranexamic acid, Whitening cream.

(c) 2020 The Authors. Published by Innovare Academic Sciences Pvt Ltd. This is an open access article under the CC BY license (http://creativecommons. org/licenses/by/4. 0/) DOI: http://dx.doi.org/10.22159/ijap.2020.v12s1.FF015

\section{INTRODUCTION}

Tranexamic acid (TA) (Fig. 1) is an antifibrinolytic agent used to treat menorrhagia. In addition, TA also has a whitening effect against hyperpigmentation caused by melasmaand ultraviolet(UV) radiation[1]. TA has been studied for its anti-melasma potential compared with standard therapy [2]. These reports revealed that oral or topical TA is similarly effective as standard therapy in patients with melasma [3]. Some studies additionally stated that TA has greater efficacy with fewer side effects. TA has emerged as a promising treatment for melasma both alone and in combination with other treatments [4-6]. TA is used as a whitening and moisturizing agent in cosmetic formulations at a concentration of $2.5 \%$ [7]. According to Japanese regulations regarding products containing TA, a cosmetic product is considered safe as a whitening agent if its TA concentration does not exceed 1.5-2\% [8]. TA can also cause severe irritation and allergies under skin conditions that are sensitive to the agent [9-11]. TA does not have a high number of chromophore groups, and thus it is difficult to detect through UV spectroscopy. Analyses of TA in pharmaceutical products through high-performance liquid chromatography (HPLC) always involve derivatization to obtain a higher number of chromophore groups. The previous studies on the derivatization of TA used derivative agents such as $0.2 \%$ ninhydrin in methanol [12], phenyl isothiocyanate [13], 2-hydroxynaphthaldehyde in ethanol [14], sodium picryl sulfonate [15], benzenesulfonyl chloride [16], and 2,4-dinitrofluorobenzene [17]. None of these studies reported direct analysis using UV-HPLC. Therefore, this study analyzed TA content in a cosmetic sample in the form of a cream without derivatization using reverse-phase HPLC. The method of sample preparation and HPLC analysis was optimized to increase its sensitivity and selectivity to permit TA analysis without derivatization through a simpler method.

\section{METHODS}

\section{Instrumentation}

An LC 20AT HPLC system (Shimadzu, Japan) was equipped with a pump, SunFire ${ }^{\mathrm{TM}} \mathrm{C}_{18}$ column, SPD-10A UV-Vis detector (Shimadzu), manual injector, and data processor (LC-Solution). A UV-Vis spectrophotometer (Jasco V-530), HPLC syringe (SGE, Australia), centrifuge (Labofuge 5100), vortex (Thermo Scientific), micropipette (Eppendorf), Ultrasonic Sonicator, hotplate (IKA ${ }^{\circledR}$ C-MAG HS 7), pH meters (Eutech Instruments $\mathrm{pH} 510$ ), and $0.45-\mu \mathrm{m}$ Whatman filter membrane were also utilized.

\section{Chemicals and reagents}

TA (Hunan Dongting Pharmaceutical Co., Ltd.), HPLC grade acetonitrile (Merck), glacial acetic acid (Merck), ammonium acetate (Merck), double-distilled water (Ikapharmindo), potassium dihydrogen phosphate (Merck), methanol (Merck), and cream whitening samples were obtained from commercial suppliers.

\section{Chromatographic conditions}

Chromatographic separation was conducted using a $\mathrm{C}_{18}$ column as the stationary phase and acetonitrile: double-distilled water: phosphoric acid $(64: 34: 2) \mathrm{v} / \mathrm{v} / \mathrm{v}$ as the mobile phase at a flow rate of $0.8 \mathrm{~mL} / \mathrm{min}$. Chromatographic detection was performed using a UV-Vis detector at a wavelength of $210 \mathrm{~nm}$.

\section{Standard and working solution preparation}

The standard stock solution of TA $(1000 \mu \mathrm{g} / \mathrm{mL})$ was prepared by dissolving $100 \mathrm{mg}$ of TA in $70 \mathrm{~mL}$ of distilled water in a $100-\mathrm{mL}$ volumetric flask. The solution was saturated for $15 \mathrm{~min}$ and solvent was added up to a volume of $100 \mathrm{~mL}$. The working solution was prepared by diluting the stock solution with solvent to obtain $200 \mu \mathrm{g} / \mathrm{mL}$ TA. 


\section{Sample preparation}

Extraction was performed by dissolving $150 \mathrm{mg}$ of a cream sample in $10 \mathrm{~mL}$ of water and the mixture was heated at $100^{\circ} \mathrm{C}$ until the sample dissolved completely. The mixture was centrifuged at $3000 \mathrm{rpm}$ for $10 \mathrm{~min}$. The supernatant was separated and filtered through a $0.45-\mu \mathrm{m}$ membrane filter. Then, $20 \mu \mathrm{L}$ of the sample were injected and the chromatogram was recorded.

\section{System suitability test}

In total, $20 \mu \mathrm{L}$ of $200 \mu \mathrm{g} / \mathrm{mL}$ TA were injected into the HPLC system under the optimal analysis conditions. The injection was repeated up to six times. The results of each trial were recorded and used to calculate the coefficient of variation (CV). The required CV was $\leq 2 \%$ [5].

\section{Method validation}

This method is validated using parameters such as selectivity, linearity, limit of detection (LOD), limit of quantitation (LOQ), accuracy, and precision.

\section{Selectivity}

Selectivity was examined by comparing the chromatogram of a blank cream solution with a standard solution around the retention time of TA. There should be no disturbance in the retention time of TA in the chromatogram of the blank solution.

\section{Linearity}

Linearity tests were performed using standard solutions at six concentrations over the range of $150-700 \mu \mathrm{g} / \mathrm{mL}$. Each concentration was obtained by diluting the $1000 \mu \mathrm{g} / \mathrm{mL}$ standard solution. The calibration curve plotted the relationship between the concentration and area using the least square method.

\section{LOD and LOQ}

LOD and LOQ were calculated using a linear regression calibration curve and an $\mathrm{Sb}$ value equal to the residual standard deviation (S[y/x]).

\section{Accuracy and precision}

Accuracy and precision tests were conducted using simulated or spiked placebo recovery methods. The standard number for each concentration of 80,100 , and $120 \%(16,20$, and $24 \mathrm{mg}$, respectively) was weighed. At each concentration, a number of matrices were added until a weight of $1 \mathrm{~g}$ was reached, and the sample was then dissolved in a $10-\mathrm{mL}$ volumetric flask followed by extraction as described in the sample preparation stage. Accuracy was calculated using the percentage of recovery (\% recovery), and precision was calculated using the percentage of the relative standard deviation based on three injections at concentrations of 80 and $120 \%$ and six injections at a concentration of $100 \%$.

\section{RESULTS AND DISCUSSION}

\section{Wavelength optimization analysis}

To determine the maximum wavelength of a compound, UV-1600 series spectrophotometers should be used in the wavelength range of $190-400 \mathrm{~nm}$. Determination of the maximum wavelength is important before the start of the analysis to permit the maximum absorption of the compounds to be analyzed using the reverse-phase HPLC system, but TA does not have sufficient numbers of chromophore and auxochrome groups to permit direct detection using UV spectrophotometry. Therefore, in this study, optimization of HPLC was performed at wavelengths of 200, 205, and $210 \mathrm{~nm}$. The results for the peak area and number of theoretical plates were greater at $210 \mathrm{~nm}$ than at the other wavelengths. Data from the selection of wavelength analysis of TA compounds are presented in Table 1.

\section{Optimization and mobile phase composition}

Mobile phase composition was optimized using three different mobile phases. Analysis of TA using a mobile phase consisting of acetonitrile: phosphate buffer $\mathrm{pH} 3.6(35: 65 \mathrm{v} / \mathrm{v})$ produced an asymmetrical peak, which was not ideal because it was difficult to determine its area. The mobile phase of acetonitrile: double-distilled water: phosphate buffer $(64: 34: 2)$ produced the best peak shape and constant. The peak was observed at $2 \mathrm{~min}$, which indicated that the method requires a short run time. Contrarily, the mobile phase of methanol: buffer $\mathrm{pH} 4$ (75:25) did not produce an analyte peak even after $15 \mathrm{~min}$ of analysis. The analytical process was terminated after $15 \mathrm{~min}$ because results were obtained with a faster retention time using acetonitrile: double-distilled water: phosphate buffer (64:34:2) as the mobile phase. Therefore, acetonitrile: double-distilled water: phosphate buffer was selected as the mobile phase because it provided the best area results, retention time, and peak among the mobile phase combinations examined. The chromatogram of the mobile phase optimization is presented in Fig. 2.

\section{Optimization of the flow rate}

To further optimize the conditions, three different flow rates, namely, $0.8,1$, and $1.2 \mathrm{~mL} / \mathrm{min}$, were compared. The three flow rates resulted in retention times of $2.151,1.727$, and $1.435 \mathrm{~min}$, respectively, and peak areas of 103629,82545 , and $103629 \mu \mathrm{V} / \mathrm{s}$, respectively.

The retention time decreased as the flow rate increased, whereas the area tended to become smaller because the separation did not occur perfectly. In addition, the pressure in the column also increased up to $100 \mathrm{kgf} / \mathrm{cm}^{2}$ as the flow rate was increased. In this study, the optimal flow rate was $0.8 \mathrm{~mL} / \mathrm{min}$ because it provided better resolution, a larger area, a large number of theoretical plates, a safe pressure

Table 1: Wavelength analysis results

\begin{tabular}{lll}
\hline Wavelength & Area $(\boldsymbol{\mu V} / \mathbf{s})$ & Number of theoretical plates \\
\hline $200 \mathrm{~nm}$ & 103629 & 2920 \\
& 93367 & 3042 \\
$205 \mathrm{~nm}$ & 110600 & 3048 \\
$210 \mathrm{~nm}$ & 101788 & 3068 \\
& 113055 & 3171 \\
& 128553 & 2975 \\
\hline
\end{tabular}

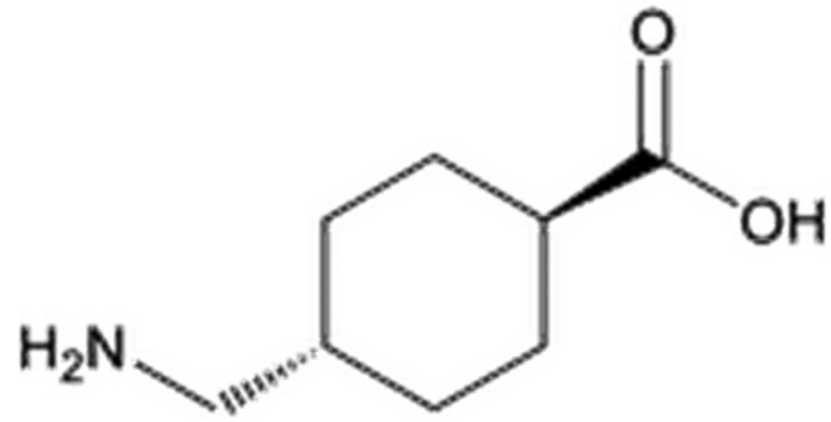

Fig. 1: Structure of tranexamic acid [6]

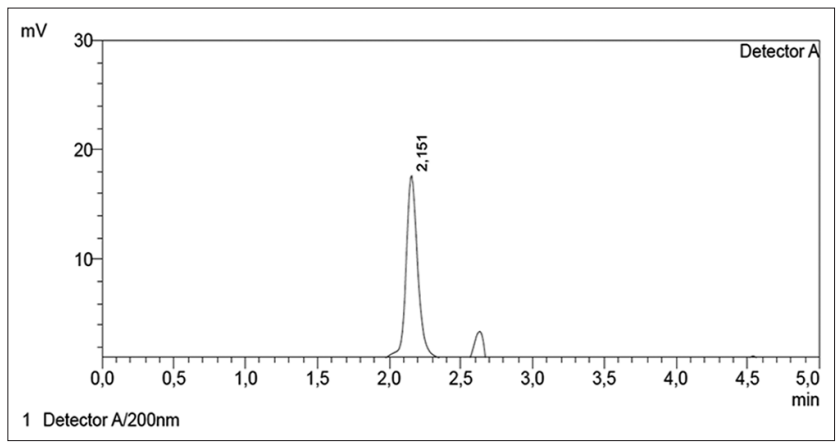

Fig. 2: Chromatogram of the standard solution of tranexamic acid 
(70-90 kgf $\left./ \mathrm{cm}^{2}\right)$, and a small height equivalent of a theoretical plate (HETP). Chromatograms and data from the selection of flow rates for TA compounds are presented in Table 2 .

\section{System suitability test}

Before choosing the optimal analysis conditions, it is important to first perform a system suitability test because there might be differences in the type of equipment and techniques used. The following results were obtained after six repeated injections: HETP, 47.515; follow-up factor, 1304; CV, 1.667\%; and number of theoretical plates, 3157. The obtained data met the requirements of the system suitability test because the CV was $<2 \%$. Data from the complete system suitability test are shown in Table 3 .

\section{Method validation}

Selectivity

Selectivity was evaluated using the chromatograms of blank, standard, and sample solutions. The results did not reveal any interference of the retention time for TA compounds, which was $2.145 \mathrm{~min}$. Injecting $20.0 \mu \mathrm{L}$ of the placebo solution (cream matrix) also resulted in no interference of the retention time of TA. In the placebo chromatogram (cream matrix), there were peaks at 0.7 and $1 \mathrm{~min}$, which were considered to represent other compounds present in the placebo. However, no other peaks were observed in the chromatogram of the placebo solution (cream matrix). This illustrated that the analytical method was selective for TA compounds. The placebo solution chromatogram (cream matrix) is presented in Fig. 3.

\section{Linearity}

A linear regression equation was obtained using six concentrations of standard solutions over the range of $150-700 \mu \mathrm{g} / \mathrm{mL}$, namely $y=543.78 x-20537$ with a correlation coefficient of 0.99915 . From the results of the analysis, it can be concluded that the calibration curve met the linearity test requirements. Data from the linear regression are presented in Table 4 and the calibration curve is shown in Fig. 5.

\section{LOD and LOQ}

The LOD and LOQ identify the smallest concentrations that can be accurately and precisely determined using a specific method, with lower values indicating greater sensitivity. Both values were calculated

Table 2: Optimization results for flow rate selection

\begin{tabular}{llllll}
\hline Flow rate & Area $(\mathbf{m V} / \mathbf{s})$ & Retention time $(\mathbf{m i n})$ & Tailing factor $($ Tf) & HETP & 51.377 \\
\hline 0.8 & 103629 & 2.151 & 1.127 & 56.818 & 2920 \\
1.0 & 82545 & 1.727 & 1.105 & 74.85 & 2640 \\
1.2 & 100705 & 1.435 & 0.739 & 2004 & Number of theoretical plates \\
\hline
\end{tabular}

Table 3: System suitability test result

\begin{tabular}{|c|c|c|c|c|c|c|}
\hline Area $(\mathrm{mV} / \mathrm{s})$ & Retention time (min) & Tailing factor (Tf) & HETP & Number of theoretical plates (n) & $\begin{array}{l}\text { Standard } \\
\text { deviation }\end{array}$ & $\begin{array}{l}\text { Coefficient of } \\
\text { variation (\%) }\end{array}$ \\
\hline 107559 & 2.145 & 1.304 & 47.515 & 3157 & \multirow{6}{*}{1826.222} & \multirow{6}{*}{1.667269601} \\
\hline 110499 & 2.143 & 1.351 & 47.754 & 3141 & & \\
\hline 109938 & 2.150 & 1.308 & 47.505 & 3158 & & \\
\hline 110752 & 2.144 & 1.296 & 48.747 & 3077 & & \\
\hline 106990 & 2.144 & 1.299 & 47.972 & 3127 & & \\
\hline 111464 & 2.148 & 1.45 & 47.515 & 2930 & & \\
\hline
\end{tabular}

Table 4: Calibration curve data, LOD, and LOQ of tranexamic acid

\begin{tabular}{lllll}
\hline Concentration $(\mathbf{m g} / \mathbf{m L})$ & Area $(\mathbf{m V} / \mathbf{s})$ & $\mathbf{S}(\mathbf{y} / \mathbf{x})^{2}$ & $\mathbf{S}(\mathbf{y} / \mathbf{x})$ & $\mathbf{L O D}(\mathbf{m g} / \mathbf{m L})$ \\
\hline 150 & 56257 & 30074678 & 5484.038 & 30.22509 \\
250 & 123447 & & \\
300 & 141759 & & \\
500 & 250373 & & \\
600 & 301124 & & \\
700 & 363272 & & \\
$\mathrm{n}=6$ & $\Sigma=120298712$ & & & \\
\hline
\end{tabular}

LOD: Limit of detection, LOQ: Limit of quantification

Table 5: Data on the accuracy and precision of tranexamic acid content analysis in cream preparations

\begin{tabular}{|c|c|c|c|c|c|c|}
\hline Concentration $(\mu \mathrm{g} / \mathrm{mL})$ & Area $(\mu V / s)$ & Calculated concentration $(\mu \mathrm{g} / \mathrm{mL})$ & SD (\%) & CV (\%) & UPK (\%) & Average (\%) \\
\hline \multirow[t]{3}{*}{239.8} & 112720 & 245.0568245 & \multirow[t]{3}{*}{1.74} & \multirow[t]{3}{*}{1.72} & 102.19 & \multirow[t]{3}{*}{101.175} \\
\hline & 108762 & 237.7781456 & & & 99.15 & \\
\hline & 112700 & 245.0200449 & & & 102.17 & \\
\hline \multirow[t]{5}{*}{300.1} & 141027 & 297.112803 & \multirow[t]{5}{*}{1.31} & \multirow[t]{5}{*}{1.31} & 99.00 & \multirow[t]{5}{*}{100.44} \\
\hline & 142770 & 300.3181434 & & & 100.07 & \\
\hline & 143386 & 301.4509544 & & & 100.45 & \\
\hline & 146719 & 307.5802714 & & & 102.49 & \\
\hline & 141437 & 297.8667844 & & & 99.00 & \\
\hline \multirow[t]{3}{*}{360.2} & 173778 & 357.3412042 & \multirow[t]{3}{*}{1.02} & \multirow[t]{3}{*}{1.02} & 99.20 & \multirow[t]{3}{*}{99.789} \\
\hline & 173747 & 357.2841958 & & & 99.19 & \\
\hline & 177235 & 363.6985546 & & & 100.97 & \\
\hline
\end{tabular}

SD: Standard deviation, CV: Coefficient of variation 


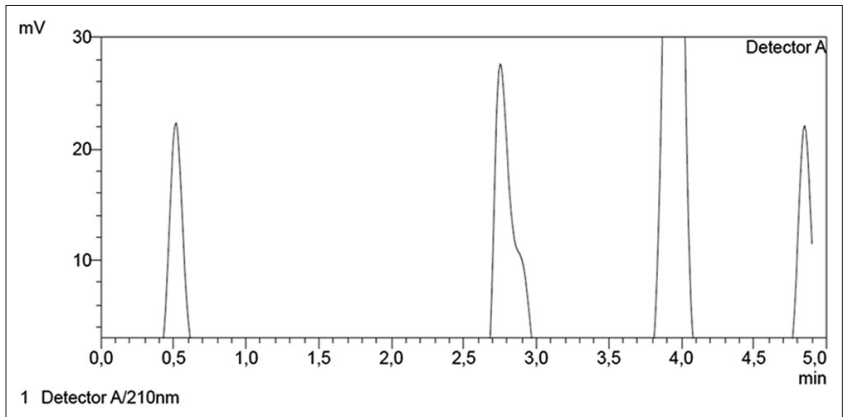

Fig. 3: Chromatogram of the cream placebo solution after extraction

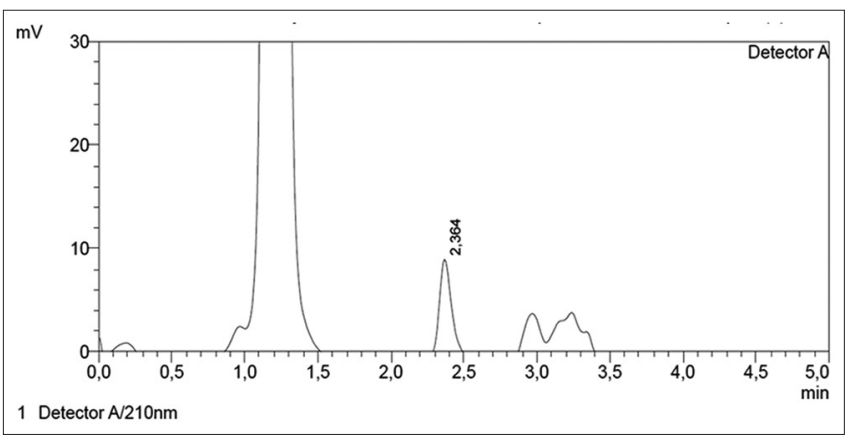

Fig. 4: Chromatogram of a sample solution of a commercially available whitening cream

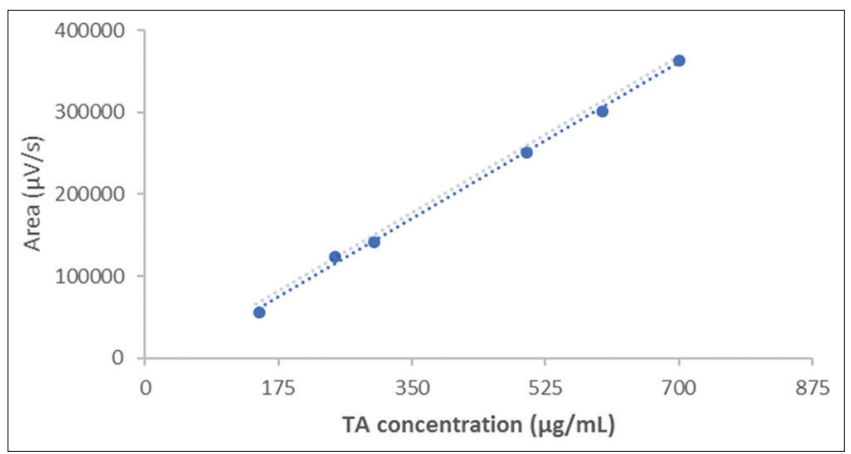

Fig. 5: Calibration curve of a standard solution of tranexamic acid

Table 6: Determination of TA levels in a commercially available bleach cream sample

\begin{tabular}{lllll}
\hline Sample & $\begin{array}{l}\text { Sample } \\
\text { weighed }(\mathbf{m g})\end{array}$ & $\begin{array}{l}\text { Area } \\
(\boldsymbol{\mu} \mathbf{V} / \mathbf{s})\end{array}$ & $\begin{array}{l}\text { Concentration } \\
(\%)\end{array}$ & $\begin{array}{l}\text { Average } \\
(\%)\end{array}$ \\
\hline $\mathrm{X}$ & 150 & 61851 & 1.00 & \\
& & 63785 & 1.03 & 1.013 \\
& & 62098 & 1.01 & \\
\hline
\end{tabular}

TA: Tranexamic acid

statistically using a linear regression line from the calibration curve. The LOD for TA solution was $30.225 \mu \mathrm{g} / \mathrm{mL}$, whereas the LOD was $100.85 \mu \mathrm{g} / \mathrm{mL}$. The results of these analyses are presented in Table 4.

\section{Accuracy and precision}

Based on the results of the analysis, the average \% recovery of TA at concentrations of 80,100 , and $120 \%$ was $101.175,100.44$, and $99.789 \%$, respectively, which all met the criterion of $98-102 \%$. Furthermore, the CVs of TA at these concentrations were 1.727, 1.316, and $1.023 \%$, respectively. These data also met the criteria for accuracy and precision, indicating that this method is suitable for analyzing TA content. The results for recovery and CV obtained in the accuracy test illustrated that the extraction method optimally separated the analyte from the mixture. The results of this analysis are shown in Table 5.

\section{Determination of TA levels in whitening cream samples}

The determination of a commercially available whitening cream sample revealed that its TA content was $1.02 \%$. This level does not exceed the limit in cosmetics of $1.5-2 \%$ [2]. From the results of the analysis, it can be concluded that the developed method can be used to analyze TA content in whitening creams. The results of the level determination data are presented in Table 6 and Fig. 4.

\section{CONCLUSION}

The optimal conditions for analyzing TA content in whitening cream preparations using reverse-phase HPLC were as follows: Water solvent, a C18 SunFire column ( $4.6 \mathrm{~mm}$ inner diameter size, $5 \mu \mathrm{m}$ particle size, and $250 \mathrm{~mm}$ column length), UV-Vis detector, mobile phase consisting of acetonitrile: double-distilled water: phosphate buffer $(64: 34: 2 \mathrm{v} / \mathrm{v} / \mathrm{v})$, wavelength of $210 \mathrm{~nm}$, and flow rate of $0.8 \mathrm{~mL} / \mathrm{min}$. The injection volume was $20.0 \mu \mathrm{L}$. The retention time of the compound peak was in the $2^{\text {nd }}$ min.

The analytical method fulfills all of the criteria for a validation method, including linearity, selectivity, precision, and accuracy, and thus the developed method was declared valid. The method is applicable for analyzing whitening cream samples, as the method identified that the TA content in a commercially available sample was $1.02 \%$.

\section{CONFLICTS OF INTEREST}

The authors declare that they have no conflicts of interest.

\section{REFERENCES}

1. Ebrahimi B, Naeini FF. Topical tranexamic acid as a promising treatment for melasma. J Res Med Sci 2014;19:753-7.

2. Perper M, Eber AE, Fayne R, Verne SH, Magno RJ, Cervantes J, et al. Tranexamic acid in the treatment of melasma: A review of the literature. Am J Clin Dermatol 2017;18:373-81.

3. Bala HR, Lee S, Wong C, Pandya AG, Rodrigues M. Oral tranexamic acid for the treatment of melasma: A review. Dermatol Surg 2018;44:814-25.

4. Pazyar N, Yaghoobi R, Zeynalie M, Vala S. Comparison of the efficacy of intradermal injected tranexamic acid vs hydroquinone cream in the treatment of melasma. Clin Cosmet Investig Dermatol 2019;12:115-22.

5. Tehranchinia Z, Saghi B, Rahimi H. Evaluation of therapeutic efficacy and safety of tranexamic acid local infiltration in combination with topical $4 \%$ hydroquinone cream compared to topical $4 \%$ hydroquinone cream alone in patients with melasma: A split-face study. Dermatol Res Pract 2018:2018:8350317.

6. Saki N, Darayesh M, Heiran A. Comparing the efficacy of topical hydroquinone $2 \%$ versus intradermal tranexamic acid microinjections in treating melasma: A split-face controlled trial. J Dermatolog Treat 2018;29:405-10

7. Maeda K, Naganuma M. Topical Trans-4-aminomethylcyclohexane carboxylic acid prevents ultraviolet radiationinduced pigmentation. J Photochem Photobiol B 1998;47:136-41.

8. Shih Y, Wu KL, Sue JW, Kumar AS, Zen JM. Determination of tranexamic acid in cosmetic products by high-performance liquid chromatography via a simple method. J Pharm Biomed 2008;48:1446-50.

9. Martindale W, Reynolds JE. Martindale: The Extra Pharmacopoeia. London (UK): Royal Pharmaceutical Society; 1996.

10. Azkiyah SZ, Supardi S, Andrajati R. The risks of using tranexamic acid and Vitamin K for decreasing prothrombin time and activated partial thromboplastin time values in intracranial hemorrhagic patients at rumah sakit umum pusat fatmawati Jakarta. Asian J Pharm Clin Res 2017;10:139-41.

11. Khan AH, Khan F, Jakram TM, Khan MA. Effects of tranexamic acid and its derivatives on the chemical and metabolic modulation of glutathione in aqueous solution. Asian J Pharm Clin Res 2009;2:27-33.

12. Natesan S, Thanasekaran D, Krishnaswami V, Ponnusamy C. Improved RP-HPLC method for the simultaneous estimation of tranexamic acid and mefenamic acid in tablet dosage form. Pharm Anal Acta 
2011;2:115-20.

13. Hadad GM, El-Gindy A, Mahmoud WM. Optimization and validation of an HPLC-UV method for determination of tranexamic acid in a dosage form and in human urine. Chromatographia 2007;66:311-7.

14. Khuwawar MY, Rind FM. HPLC determination of tranexamic acid in pharmaceutical preparations and blood. Chromatographia 2001;53:709-11.

15. Nojiri S, Uehara S, Hagiwara T, Nishijima M. High Performance Liquid Chromatographic Determination of Aspartic Acid, Taurine, and Tranexamic Acid by Precolumn Derivatization Using Sodium
Picrylsulfonate. Vol. 46. Tokyo-toritsu Eisei Kenkyusho Kenkyu Nenpo Annual Report; 1995. p. 58-61.

16. Ashfaq M, Aslam A, Mustafa G, Danish M, Nazar MF, Asghar MN. Derivatization/chromophore introduction of tranexamic acid and its hplc determination in pharmaceutical formulations. J Assoc Arab Univ Basic Appl 2015;17:51-6.

17. Patil R, Ahmed AK, Firke S, Pawar D. RP-HPLC PDA analysis of tranexamic acid in bulk and tablet dosage form. Anal Chem Lett 2017;7:813-21. 